\title{
THE PARADIGMATIC AND SYNTAGMATIC STRUCTURE OF THE LEXICAL FIELD OF FEELING1
}

\author{
Pamela Faber \\ Departamento de Filología Inglesa \\ Universidad de Granada \\ Ricardo Mairal Usón \\ Departamento de Filología Inglesa \\ Universidad Nacional de Educación a Distancia
}

\begin{abstract}
RESUMEN: En este artículo se analiza la estructura interna del dominio léxico de SENTIMIENTO, en cuanto a la interfaz entre su jerarquía semántica y los patrones de complementación de sus miembros. De esta manera, puede decirse que semántica y sintaxis convergen en una representación del conocimiento. Se utiliza la naturaleza jerárquica de esquemas cognitivos a nivel de dimensión para mostrar cómo la gradación implícita en ellos refleja niveles de prominencia conceptual. Este análisis permite poner en relieve parámetros de categorización, que realzan perspectivas diferentes sobre nuestra representación mental de los sentimientos.
\end{abstract}

ABSTRACT: In this paper we analyze the internal structure of the lexical field of FEELING, structured in hierarchies of meaning and subcategorization patterns as the codification of knowledge representation. We use the hierarchical nature of the dimension-level schemata that define this lexical field to show how hierarchical grading reflects conceptual saliency. The most significant parameters of categorization are brought to light, each of which highlights a different aspect of how feelings are represented in our mind.

\section{Introduction}

In recent years, linguists have become aware of the significance of lexical structure as a means of ascertaining and exploring the organization of concepts in the mind. It is our belief that analyzing lexical items in terms of their location and

1. This is part of the research project funded by the Vicerrectorado de Investigación of the University of La Rioja 95 PYBI5FRI 
interrelationships in semantic space makes the lexicon of a language doubly meaningful. Instead of a random list of lexical items and their idiosyncratic properties, the lexicon becomes an intricate network of elements interconnected by cohesive, associative, lexical and encyclopedic functions, which are themselves representations of categorizing relationships.

In this paper we analyze the internal structure of the lexical field of FEELING, structured in hierarchies of meaning and subcategorization patterns as the codification of knowledge representation. We use the hierarchical nature of the dimension-level schemata that define this lexical field to show how hierarchical grading reflects conceptual saliency. Moreover, we discuss the dynamic nature of this field within what we have termed the semantic macronet.

\section{Methodological preliminaries}

The lexicological model we have used to structure the lexical field of FEELING is the Functional-Lexematic model elaborated by Martín Mingorance (1984; 1985ab; 1987abc; 1990), which integrates Coseriu's Theory of Lexematics (Coseriu 1977) and Simon Dik's Functional Grammar (Dik 1978ab, 1989). A full description of this model is beyond the scope of this article, but can be found in previous publications (Martín Mingorance 1990; Faber and Mairal 1994b). The two main objectives sought within this lexicological model are firstly, the specification of the semantic architecture of the lexicon of a language, and secondly, the representation of knowledge based on the linguistic encoding found in dictionary entries ${ }^{2}$. These objectives are mutually dependent in the sense that the former serves as the input for the latter.

The structure of our lexicon consists of the paradigmatic and the syntagmatic axes. On the paradigmatic axis, lexical items are arranged onomasiologically in semantic fields, while the syntagmatic axis specifies the complementation patterns of a given predicate using predicate frames as integrated formulae. Given that these axes maintain a complementary relationship in our model, the information codified on the paradigmatic axis is influential in the delineation of complement meanings and vice versa.

In line with our idea that knowledge representation is linguistically motivated, we have formulated a typology of cognitive conceptual schemata that permeate the structure of the lexicon ${ }^{3}$.

2. In Artificial Intelligence, and more specifically in Knowledge Engineering, these two stages coincide with what is known as 'the externalisation of knowledge' and the 'formalisation of the externalised knowledge' (cf. Connolly 1990: 221).

3. For a full account of the typology of cognitive schemata in the lexicon see Faber and Mairal (forthcoming). 
To obtain the meaning components on the basis of which the definition of each lexical unit is elaborated, we have consulted five of the most widely-used dictionaries. This procedure can be justified for the following reasons:

(i) Standard dictionaries contain the body of knowledge gathered by lexicographic tradition.

(ii) Such definitions have the status of referential authority for users of the language in question.

(iii) Generally speaking, dictionary definitions provide a basis for extracting the stocks of more generic terms, which are intuitively felt by most speakers to be close the status of archilexemes. (cf Martin Mingorance 1984, 229).

In this way, structured definitions are obtained, which in turn form the meaning hierarchies that are the basic architecture of our lexical fields. Although dictionaries are generally inconsistent in the way they define words, they nevertheless are a treasure house of information for the factorization of lexemes into meaning components.

The meaning components we have used are natural language phrases found in definitions. Each definition in our lexicon is conceived as a syntactic frame with slots, having certain selection restrictions and default values. Each verb in the lexicon can be said to activate its own scenario, which determines its semantic participants/actants to a fairly specific degree. The archilexeme or superordinate term of each field is determined through stepwise lexical decomposition (Dik 1978), method used to establish the semantic hierarchy within lexical domains.

Lexical dimensions in each field are organized in terms of oppositions formulated from the definitional structure of the lexical units. These oppositions characterize both the internal structure of the domain in question as well as the lexical structure of the items it contains. Lexical dimensions are thus directly derived from the definitional structure of lexical units (Coseriu and Geckeler 1974). In this way, we have obtained the criteria to assign units to a specific domain, as well as to determine and classify their relevant interrelationships both on a micro- and macro-structural level. The lexicon is thus conceived as a structured whole divided into lexical fields, interconnected by a rich network of relations based on paradigmatic and syntagmatic features.

\section{The semantic architecture of the field of FEELING}

FEELING is the conceptual label we have given to the lexical field which symbolizes how we perceive and generally talk about affective states of consciousness (as opposed to cognitive and volitional states). Limitations of space have obliged us to 
restrict our analysis to verbs. We have chosen verbs for our study rather than nouns or adjectives because more than any other word class, they determine the structure of linguistic expressions. From valence theory, it is well-known that each verb carries its own syntactic frame and argument structure. It is our assertion that verbs also are influential in the determination of categorization parameters on the paradigmatic axis in an onomasiologically structured lexicon.

The inventory of verbs and the meaning components of their respective defintions have been compiled from six different dictionaries and re-structured according to the premises of the Functional-Lexematic Model. The dictionaries used in this study were Collins Cobuild, Longman Lexicon of Contemporary English, Oxford Advanced Learners' Dictionary, Webster's New World Dictionary for Young Readers, and The Random House Dictionary of the English Language.

We have found that the structure of FEELING is sharply polarized in terms of positive and negative feelings. The dimensions derived from the bottom-up analysis of definitional components are the following:

(1) Lexical dimensions established for the lexical field of FEELING

1. Feeling (to become aware of sth other than sight, having a sensation)

1.1. To feel sth bad

1.2. To feel sth good

1.3. To feel sadness

1.4. To feel happiness

1.5. To feel aversion producing:

1.5.1. disgust

1.5.2. anger

1.6. To feel attraction

1.6.1. To feel a loss of attraction

1.7. To feel sth bad in your body

1.7.1. To cause sb to feel less physical/mental suffering/pain

1.8. To feel fear/ anxiety (fear about bad things happening in the future)

1.8.1. To feel less fear/worry/anger

1.9. To feel surprise

1.10. To feel shame

1.11. To feel a need to do sth or to have / get sth

1.12. To cause sb to feel hope/courage

1.13. To cause sb to lose (not to feel) hope/courage/confidence

\subsection{Dimension-level schemata and conceptual saliency: categorization parameters}

The lexical field of FEELING has various dimensions, each of which highlights it from a different perspective. However, certain dimensions are more central or 
prototypical than others. This hierarchical organization or grading is intimately bound to how we categorize a given lexical domain in our mind.

The archilexeme of each field can be considered as the prototype, and as such, it marks the topic and introduces us into the universe of discourse, setting up the frontiers and paths of a given domain. In the definitional structure of the archilexeme, we find encoded the major categorization parameters of the domain.

In FEELING, the superordinate term is feel, verb whose linguistic characterization gives us the following categorization parameters:

(2) Feelings expressing an awareness of a phenomenon in the outside world [He felt the earthquake tremors/the tension/the sadness in the room.]

(3) Feelings expressing the physical/mental/emotional state of the experiencer [ I feel cold/brilliant/sad].

(4) Feelings expressing a strong idea based on intuition (not on evidence). This covers both intuitions about immediate situations [He felt that he was despised] and about future ones [He felt that the trial would be over quickly].

We postulate that these categorization parameters are basic to linguistic encoding, and in fact, focalize and subsume different dimension-level schemata. It is true that not all feelings are emotions in the strictest sense of the word. Indeed language tells us that we can feel with our senses and our mind, as well as with our heart:

(5) We felt the love of the congregation in the church. [Feeling is becoming aware through one's senses]

(6) We felt that we loved him. [Feeling is becoming aware in one's mind]

(7) We felt love for him. [Feeling is becoming aware of an affective state of consciousness (situated in the heart as opposed to the mind)]

The fuzzy nature of the boundaries between the categories of physical, mental, and emotional perception are reflected in the definitions and complementation patterns of the archilexeme, feel.

Feel [FEELING] in its most basic sense encodes a type of awareness or general perception. It is a metaphorical extension of feel [TACTILE PERCEPTION], a dyadic predicate with an experiencer and a concrete percept with shape and form.

(8) feel [TACTILE PERCEPTION]: to touch sth deliberately with one's hand.

\section{SVO}

(a) $\mathrm{S}=$ prototyp. animate $(\mathrm{Exp})$

(b) $\mathrm{O}=$ prototyp. concrete with shape and form (Percept) 


$$
\begin{aligned}
& \text { feel }_{\mathrm{V}}\left[\left(\mathrm{x}_{1} \text { : prototyp. animate }\right)_{\operatorname{Exp}}\left(\mathrm{x}_{2} \text { : prototyp. artifact }\right)_{\text {Phen }}\right]_{\text {ExpAct }} \\
& \mathrm{df}=\operatorname{touch}_{\mathrm{V}}\left(\mathrm{x}_{1}\right)_{\operatorname{Exp}}\left(\mathrm{x}_{2}\right)_{\text {Phen }}\left(\mathrm{y}_{1} \text { :deliberately }\right)_{\text {Manner }}\left(\mathrm{y}_{2} \text { : one's hand }\right)_{\text {Instr }}
\end{aligned}
$$

Ex. Can you feel the bump on my wrist?

In the above example, the selection restrictions of the second argument delimit it to the extent that it must be something that the experiencer can touch purposively with his/her hand. However, if this argument slot is occupied by an abstract entity, then the basic meaning of feel changes, and there is a corresponding change of lexical field as well. The status of feel is much more important in FEELING than it was in TACTILE PERCEPTION, as in this field it is the archilexeme, and as such, has prototypical status with a much greater variety of complementation patterns, which as shall be seen, logically play an important role in determining the structure of the field as a whole.

\subsubsection{To feel, being aware of a phenomenon in the outside world}

The first complementation pattern of FEELING, in which the first categorization pattern is instantiated, is the following:

(9) feel2 [FEELING]: to have a sensation of sth other than sight and to be aware of it.

SVO

(a) $\mathrm{S}=$ prototyp. animate (Exp)

(b) $\mathrm{O}=$ prototyp. physical/emotional (Phen)

feel $_{\mathrm{V}}\left[\left(\mathrm{x}_{1} \text { : prototyp. animate }\right)_{\operatorname{Exp}}\left(\mathrm{x}_{2}\right.\right.$ : prototyp. physical/emotional percept) ${ }_{\text {Phen }}{ }_{\text {ExpSt }}$

$\mathrm{df}=\operatorname{sense}_{\mathrm{V}}\left(\mathrm{x}_{1}\right)_{\operatorname{Exp}}\left(\mathrm{x}_{2} \text { : physical/emotional }\right)_{\text {Phen }}\left(\mathrm{y}_{1}:\left[\mathrm{e}_{1}\right.\right.$ : become aware $\mathrm{b}_{\mathrm{V}}$ $\left.\left(\mathrm{x}_{1}\right)\right]_{\text {Manner }}$

Ex. Can you feel the earthquake tremors? [exterior physical phenomenon] She felt her heartbeat quicken. [interior physical phenomenon] You could feel the sadness at the funeral. [exterior emotional phenomenon] They had felt a great love for him. [interior emotional phenomenon]

This categorization parameter highlights the experiencer's perception of a physical/emotional process that can either be internal or external to the experiencer, who in this case moves from a state of unawareness to one of awareness. As a result, this pattern reflects strong connections with those typical of the fields of PERCEPTION and COGNITION. 


\subsubsection{To feel sth physical/mental/emotional}

In this second categorising parameter, feelings originate within and affect an experiencer provoking certain changes in him/her. As a result, these predicates show connections with those in the field of CHANGE (the end result of any type of movement).

(10) SV-Complement [to be in a physical/emotional/moral state]

(a) $\mathrm{S}=$ prototyp. animate (Exp)

(b) $\mathrm{O}=$ prototyp. state <body condition>, <experiencer's response>, <experiencer's physical/mental/emotional state> (Phen)

feel $_{\mathrm{V}}\left[\left(\mathrm{x}_{1} \text { : prototyp. animate }\right)_{\operatorname{Exp}}\left(\mathrm{x}_{2}\right.\right.$ : prototyp. state < body condition>, <experiencer's response>, <experiencer's physical/mental/emotional state>) $\left.{ }_{\text {Phen }}\right]_{\text {ExpSt }}$

e.g. I felt cold/brilliant/sad.

In the above example, the experiencer is focalized. However, the SVC pattern does not so much lexicalize a process of internal awareness as a state of being. Thus in this sense, FEELING is connected with EXISTENCE (to be in a certain state).
(11) I feel cold.
$\Rightarrow \quad$ I am cold.
[physical state]
(12) I feel brilliant.
$\Rightarrow \quad$ I am brilliant.
[mental state]
(13) I feel sad.
$\Rightarrow \quad$ I am sad.
[emotional state]

The arrow does not indicate equality except perhaps in example (13). In this case, feeling sad is the same as being sad, because the experiencer is the only possible judge of his state of consciousness. However, feeling is not necessarily the same as being when the truth of the complement meaning depends more on the perceptions of others than on one's own. For example, one can feel rich with very little money in one's pocket, but not actually be so according to social norm.

\subsubsection{To feel sth is the case}

This third categorization parameter connects FEELING with COGNITION. To feel is basically to experience something and to be aware of it. Although language establishes a rigid dichotomy of feeling and reason, heart and head, as well as body and mind, the separation is more apparent than real. Feeling may be a metaphorical extension of touch, our "blindest" sense, but it is also used for cognition, more 
specifically to refer to intuition, that parcel of mental perception in which we know something, but without knowing why or how we know it.

(14) SVO-that clause

(a) $\mathrm{S}=$ prototyp. animate (Exp)

(b) $\mathrm{O}=$ prototyp. subjective probable fact

feel $_{\mathrm{V}}\left[\left(\mathrm{x}_{1} \text { : prototyp. animate }\right)_{\operatorname{Exp}}(\text { ProbX })_{\mathrm{Phen}}\right]_{\mathrm{ExpSt}}$

e.g. He felt that there was no hope.

They felt that their luck would change.

\section{SVO}

(a) $\mathrm{S}=$ prototyp. animate (Exp)

(b) $\mathrm{O}=$ Concealed proposition (probable fact) (Phen)

feel $_{\mathrm{V}}\left[\left(\mathrm{x}_{1} \text { : prototyp. animate }\right)_{\operatorname{Exp}}(\text { ProbX })_{\text {Phen }}\right]_{\text {ExpSt }}$

e.g. He felt a prize idiot.

SVO (headed by like or as if /as though)

(a) $\mathrm{S}=$ prototyp. animate (Exp)

(b) $\mathrm{O}=$ Concealed proposition (probable fact) (Phen)

feel $_{\mathrm{V}}\left[\left(\mathrm{x}_{1} \text { : prototyp. animate }\right)_{\operatorname{Exp}}(\text { ProbX })_{\text {Phen }}\right]_{\text {ExpSt }}$

e.g. I feel like a thief.

I feel as if/though I am a thief.

He felt (like) a thief $=$ He felt that he was a thief.

He felt despised $=$ He felt as though/like/that he was despised.

\subsection{Dimension-level schemata}

The categorization patterns manifest in the argument structure of feel are instantiated in the following dimensions of the lexical field of FEELING. These fall into four groups, classified in terms of their focus on specific components of event structure: (i) to feel a physical/mental sensation; (ii) to feel an emotion (focus on state); (iii) to feel an emotion (focus on entity/event triggering it); (iv) to feel an emotion (focus on the reaction of the experiencer).

\subsubsection{To feel a physical/mental sensation}

This parameter subsumes the following nuclear dimensions: (i) to feel/experience sth bad in your body (physical suffering or pain); (ii) to cause sb to feel physical/mental suffering or pain. 
It is important to stress here the virtual impossibility of separating the mind from the body (Johnson 1987, 1992; Moyers 1993). As we have previously mentioned, many of these verbs, especially those of causative suffering (to cause sb to feel sth bad) can refer to both physical and mental pain. Hurt, ache, pain, wound, torment and torture all do double duty in this area, referring to both types of suffering.

The syntactic realization of the non-causative dimension is projected from the following predicate schema:

$\left[\left(\mathrm{x}_{1} \text { : prototyp. human }\right)_{\mathrm{Exp}}\right]$ State

This schema is instantiated in the following examples:

(15) ache: to feel a dull, steady pain

SV

(a) $\mathrm{S}=$ prototyp. human or part of one's body (Exp)

e.g. Every time it rained his knee ached. [physical sensation]

I ached to comfort him. [mental sensation]

ache $_{\mathrm{V}}\left[\left(\mathrm{x}_{1} \text { : prototyp. human }\right)_{\mathrm{Exp}}\right] \mathrm{St}$

$\mathrm{df}=\operatorname{feel}_{\mathrm{V}}\left(\mathrm{x}_{1}\right)_{\operatorname{Exp}}\left(\mathrm{x}_{2}\right.$ : pain: dull:steady) Phen

smart: to feel a sharp stinging pain

SV

(a) $\mathrm{S}=$ prototyp. human <a part of one's body $>$ (Exp)

$\operatorname{smart}_{\mathrm{V}}\left[\left(\mathrm{x}_{1} \text { : prototyp. human }\right)_{\mathrm{Exp}}\right] \mathrm{St}$

$\mathrm{df}=\mathrm{feel}_{\mathrm{V}}\left(\mathrm{x}_{1}\right)_{\operatorname{Exp}}\left(\mathrm{x}_{2} \text { : pain: sharp:stinging }\right)_{\text {Phen }}$

e.g. His eyes smarted from the thick smoke. [physical sensation]

I smarted from his sharp rebuke. [mental sensation]

The causative dimension activates a different predicate schemata, thus incorporating a new argument to the predicate:

(16) pain: to hurt (old fashioned)

SVO

(a) $\mathrm{S}=$ prototyp. human <part of one's body > (Ag)

(b) $\mathrm{O}=$ prototyp. human (Go)

e.g. The soldier winced because his wounded shoulder pained him. 
SVO

(a) $\mathrm{S}=$ prototyp. a negative situation or entity $(\mathrm{Ag})$

(b) $\mathrm{O}=$ prototyp. human <one's mind> (Go)

e.g. It pained them that he had to die.

pain $_{\mathrm{V}}\left[\left(\mathrm{x}_{1} \text { : prototyp. human <part of one's body> }\right)_{\mathrm{Ag}}\left(\mathrm{x}_{2}\right.\right.$ : prototyp. human) ${ }_{\mathrm{Go}}$ /Aff $]_{\text {Action }}$

$\mathrm{df}=\operatorname{hurt}_{\mathrm{v}}\left(\mathrm{x}_{1}\right)_{\operatorname{Exp}}$

Evidence that these verbs are applicable both to the physical and mental world is present in the definitional structure (paradigmatic axis) and the argument structure (syntagmatic axis).

\subsubsection{To feel an emotion: focus on state}

This parameter is reflected in the lexical dimensions, to feel/experience sadness and to feel/experience happiness. These dimensions firstly focus the experiencer's emotional state, and secondly the cause of this state. These categorization parameters are also reflected in the syntactic symbolic units that embody the dimension-level schemata. Accordingly, given this semantic-conceptual characterization, the predicates subsumed within these dimensions subcategorize the following general predicate schema:

\section{$\left[\left(\mathrm{x}_{1} \text { : prototyp. human }\right)_{\operatorname{Exp}}\left(\mathrm{x}_{2} \text { : prototyp. event/cause }\right)_{\mathrm{Phen}}\right]_{\mathrm{St}}$}

These predicates activate a scenario which in turn designates a state characterized by two arguments, the first, qualified protoypically as an experiencer, and a second argument which is the cause of the experiencer's emotional state.

This general framework activates two different predicate subschemata depending on the semantic and syntactic nature of the second argument. An analysis of the semic features present in the definitions of these lexemes indicates that the experiencer feels sad either because of the absence or disappearance of somebody/something (whose presence is desired), or because something unpleasant has happened.

As can be seen in the following examples, these two semantic features correlate with two different complementation patterns ${ }^{4}$ : (i) noun phrase or prepositional phrase; (ii) infinitive or gerund clause:

4. Note that there is a convergence between the paradigmatic and syntagmatic axis. This has led us to postulate a number of Lexical Iconic Principles that validate this diagrammatic correlation between semantics (as codified in the paradigmatic axis) and syntax (as codified in the syntagmatic axis (Faber and Mairal 1994ab, forthcoming). 


\section{(17) To feel/experience sadness}

mourn: to grieve (usu. because sb has died or sth is permanently lost)

SVO

(a) $\mathrm{S}=$ prototyp. human (Exp)

(b) $\mathrm{O}=$ prototyp. human or someone's death (Phen)

e.g. America mourned the death of Kennedy.

SVPO (for)

(a) $\mathrm{S}=$ prototyp. human (Exp)

(b) $\mathrm{O}=$ prototyp. human or someone's death (Phen)

e.g. The whole family will always mourn for her.

pine: to grieve for a long time, not wanting to eat or do anything.

$\mathrm{SV}$

(a) $\mathrm{S}=$ prototyp. person or animal (Exp)

e.g. She certainly didn't pine while her husband was lost at sea.

SVPO (for)

(a) $\mathrm{S}=$ prototyp. person or animal (Exp)

(b) $\mathrm{O}=$ prototyp. human <someone's death or absence> (Phen)

e.g. She became very thin and spent all day pining for him.

SVO-inf

(a) $\mathrm{S}=$ prototyp. person or animal (Exp)

(b) $\mathrm{O}=$ sth that $\mathrm{S}$ wants to do and cannot

e.g. We were pining to get back to the island once more.

pity: to feel sorry for sb (usu. their suffering or bad luck) SVO

(a) $\mathrm{S}=$ prototyp. human (Exp)

(b) $\mathrm{O}=$ prototyp. human <someone's misfortune> (Phen)

e.g. The people in the courtroom seemed to pity the fate of the accused.

SVO PO (for)

(a) $\mathrm{S}=$ prototyp. human (Exp)

(b) $\mathrm{O}=$ prototyp. human <someone's misfortune> (Phen)

(c) $\mathrm{PO}=$ prototyp. the cause why $\mathrm{S}$ feels sad (Cause)

e.g. I pitied her for what she had been through.

regret: to feel sorry about something, wishing you had not done it / that it had not happened.

SV Complement

(a) $\mathrm{S}=$ prototyp. human (Exp)

(b) $\mathrm{O}=$ prototyp. a mistake, sad fact or event (Phen). Cases of concealed propositions. 
e.g. We regret that the schedule could not be changed.

You'll regret your choice.

SVO-Ing Clause

(a) $\mathrm{S}=$ prototyp. human (Exp)

(b) $\mathrm{O}=$ prototyp. objective certain event (Phen). This event is negative with respect to an ICM.

e.g. They regretted not having spent more time with him.

rue: to regret sth deeply (formal) (old-fashioned).

SVO

(a) $\mathrm{S}=$ prototyp. human (Exp)

(b) $\mathrm{O}=$ prototyp. a mistake, sad fact or event (Phen). Case of a concealed proposition which is negatively axiologically loaded.

e.g. She rued the day that she received that letter.

repent to feel sorry for sth bad done in the past.

SVO

(a) $\mathrm{S}=$ prototyp. human (Exp)

(b) $\mathrm{O}=$ prototyp. something bad $\mathrm{S}$ had done (Phen). (cf. axiological load).

e.g. He repented his evil ways.

SV PO (of/for)

(a) $\mathrm{S}=$ prototyp. human (Exp)

(b) $\mathrm{PO}=$ prototyp. something bad $\mathrm{S}$ had done (Phen). (cf. axiological load).

e.g. He went to confession to repent of his wrongdoings.

SVO-Ing Clause

(a) $\mathrm{S}=$ prototyp. human (Exp)

(b) $\mathrm{O}=$ prototyp. objective certain event (Phen). This event is conceptualized as negative (cf. axiological load).

e.g. They repented not having studied for the exam.

The general predicate schema is split into the following two predicate subschemata:

(18) General predicate schema:

$\left[\left(\mathrm{x}_{1} \text { :prototyp. human }\right)_{\operatorname{Exp}}\left(\mathrm{x}_{2}: \mathrm{NP} / \mathrm{PP}\right.\right.$ prototyp. <absence/disappearance of sth/ sb>) Reason] State.

Subschema 1: [( $\mathrm{x}_{1}$ :prototyp. human $)_{\operatorname{Exp}}\left(\mathrm{x}_{2}\right.$ :Ing-Clause prototyp. objective certain event) Reason] State.

Subschema 2: [( $\mathrm{x}_{1}$ :prototyp. human $)_{\operatorname{Exp}}\left(\mathrm{x}_{2}:\right.$ NP prototyp. objective certain event) Reason] State. 
The second predicate subschema in turn activates two other subschemata since some of these verbs can take a noun phrase or a gerund clause. Though different on the surface, both convey the same meaning, and following Grimshaw (1979), we have classified them as concealed propositions.

\subsubsection{To feel an emotion: focus on the entity/event that produces the emotion}

This categorizing parameter focuses the way the speaker manifests his feeling towards an entity in the outside world. The meaning components within this group highlight the different ways the speaker shows his feelings. The dimension-level schemata sensitive to this categorization parameter are to feel/experience aversion/dislike and to feel/experience attraction/interest.

In both these dimensions, there is an obvious scale of intensity in parts of the hierarchy. For example, in the positive dimension, the loved entity becomes increasingly elevated in status until he/she is perceived as a god. The same is also true in the negative dimension, but in the opposite sense:

(19) To feel attraction/interest: love $->$ adore $->$ worship $->$ idolize $->$ deify

To feel hatred/dislike: dislike $->$ hate $->$ abhor $->$ detest $->$ execrate $->$ loathe

Consequently, verbs of this type subcategorize the following predicate schema, or symbolic formula that encapsulates the different syntactic and semantic realizations of the predicates under these dimensions:

$\left[\left(\mathrm{x}_{1} \text { : prototyp. human }\right)_{\operatorname{Exp}}\left(\mathrm{x}_{2}\right.\right.$ : prototyp. + concrete axiologically loaded $) \mathrm{Phen}{ }^{]} \mathrm{St}$

The axiological weight of the second argument $\left(\mathrm{x}_{2}\right)$ depends on the positive or negative nature of the dimension-level schema that subsumes that predicate. Moreover, this predicate schema activates the following subschemata:

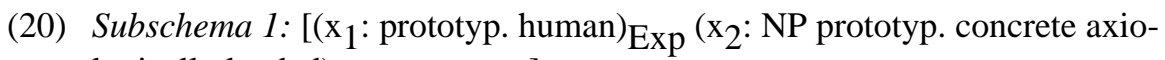
logically loaded) Phenomenon] State.

Subschema 2 : $\left[\left(\mathrm{x}_{1} \text { : prototyp. human }\right)_{\operatorname{Exp}}\left(\mathrm{x}_{2}\right.\right.$ : Inf-Clause prototyp. an event <axiologically loaded>) Phenomenon $]_{\text {State }}$

Subschema 3: [( $\mathrm{x}_{1}$ : prototyp. human $)_{\operatorname{Exp}}\left(\mathrm{x}_{2}\right.$ : Ing-Clause prototyp. an event <axiologically loaded>) Phenomenon] State.

In the above formulae, it can be observed that not only does the experiencer show his/her attitude towards an entity in the outside world, but also towards an event or state of affairs. Verbs like love, like, adore, worship, admire and their negative 
counterparts dislike, hate, abhor, detest, execrate, and loathe are activated through this predicate schemata, as can be seen in the following examples:

(21) To feel/experience aversion/dislike

hate: to dislike $\mathrm{sb} / \mathrm{sth}$ extremely and intensely.

SVO

(a) $\mathrm{S}=$ prototyp. human (Exp)

(b) $\mathrm{O}=$ prototyp. human or unpleasant entity (Phen). If human, this can be reflexive.

e.g. He hates his neighbour because she is so nosy.

They hate potato salad.

He hated himself when he saw what he had done.

SVO

(a) $\mathrm{S}=$ prototyp. human (Exp)

(b) $\mathrm{O}=$ prototyp. state of affairs that irritates (a) (Phen). Concealed proposition.

e.g. We hate it when there are long lines in the supermarket.

I hate late arrivals.

SVO-Ing (Like-Subject Constraint)

(a) $\mathrm{S}=$ prototyp. human (Exp)

(b) $\mathrm{O}=$ prototyp. objective possible action (Phen)

e.g. She hates making others wait for her.

SVO-Ing (Unlike-Subject Constraint)

(a) $\mathrm{S}=$ prototyp. human (Exp)

(b) $\mathrm{O}=$ prototyp. objective possible action (Phen)

e.g. He hates others telling him what to do.

SVO-Infinitive (Like-Subject Constraint)

(a) $\mathrm{S}=$ prototyp. human (Exp)

(b) $\mathrm{O}=$ prototyp. objective possible action (Phen)

e.g. They hate to be given advice.

SVO-Infinitive (Unlike-Subject Constraint)

(a) $\mathrm{S}=$ prototyp. human (Exp)

(b) $\mathrm{O}=$ prototyp. objective possible action (Phen)

e.g. I'd hate him to have to go there by himself.

To feel / experience attraction or interest

like: to feel attraction for $\mathrm{sb} / \mathrm{sth}$ finding them pleasant/attractive/ interesting.

SVO

(a) $\mathrm{S}=$ prototyp. human (Exp)

(b) $\mathrm{O}=$ prototyp. human (Phen)

e.g. All the students like him as a teacher. 
SVO

(a) $\mathrm{S}=$ prototyp. human (Exp)

(b) $\mathrm{O}=$ prototyp. state of affairs or entity that is pleasant to $\mathrm{S}$ (Phen). Concealed proposition.

e.g. We like meat once a week.

SVO-Infinitive (Like-Subject Constraint)

(a) $\mathrm{S}=$ prototyp. human (Exp)

(b) $\mathrm{O}=$ prototyp. objective certain action (Phen)

e.g. I like to talk to you every day.

SVO-Infinitive (Unlike-Subject Constraint)

(a) $\mathrm{S}=$ prototyp. human (Exp)

(b) $\mathrm{O}=$ prototyp. objective certain action (Phen)

e.g. Her brother likes her to wash the dishes.

SVO-Ing (Like-Subject Constraint)

(a) $\mathrm{S}=$ prototyp. human (Exp)

(b) $\mathrm{O}=$ prototyp. objective certain action (Phen)

e.g. She doesn't like washing the dishes.

The two archilexemes, hate and like, introduce us into the syntactic and semantic universe of these two dimension-level schemata. In consonance with our Principle of Lexical Iconicity (Faber and Mairal 1994a), these integrated formulae are based on the uniform syntactic and semantic behaviour of the predicates that make up these dimensions.

\subsubsection{To feel an emotion: focus on the reaction of the experiencer}

The fourth categorizing parameter expresses the reaction of the experiencer towards an external stimulus. This parameter focalizes the type of effects that a feeling causes in the experiencer. According to our typology of semes, these effects mainly affect behaviour, physical and mental functions, and cognition. The dimensions which encode this conceptualization are the following:

(22) To cause aversion/dislike in someone producing anger

To cause attraction/interest in someone

To feel/experience fear/anxiety (fear about bad things happening in the future)

The syntax of these predicates is projected onto the following predicate schemata: 
$\left[\left(\mathrm{x}_{1} \text { : prototyp. human }\right)_{\mathrm{Ag}}\left(\mathrm{x}_{2}\right.\right.$ : prototyp. + concrete negatively axiologically loaded) Go/Aff] Action

These predicates designate a state of affairs which is an action that requires two arguments. The first argument $\left(\mathrm{x}_{1}\right)$ performs the function of agent, and the second argument $\left(\mathrm{x}_{2}\right)$ is axiologically loaded. It is interesting to note that when the first argument is a situation or feeling, the second argument is usually a human entity, as can be seen in the following examples:

(23) To cause aversion or dislike in sb producing disgust

sicken: to make sb feel so disgusted that they do not feel well.

SVO

(a) $\mathrm{S}=$ prototyp. unpleasant entity <attitude, behaviour etc. > (Ag)

(b) $\mathrm{O}=$ prototyp. human (Go, Aff).

e.g. The corruption of the government sickened the people.

To cause aversion or dislike in sb producing anger

anger: to cause sb to feel anger (strong displeasure usu. because of a wrong and often leading to a desire to punish/harm the person responsible for it).

SVO

(a) $\mathrm{S}=$ prototyp. a negative axiologically loaded condition, state of affairs (Ag)

(b) $\mathrm{O}=$ prototyp. human (Go)

e.g. The theft of her jewels will no doubt anger her.

\section{SVO}

(a) $\mathrm{S}=$ prototyp. human $(\mathrm{Ag})$.

(b) $\mathrm{O}=$ prototyp. human (Go)

e.g. He will anger you when he begins to give orders.

To cause aversion or interest in someone

attract: to cause attraction/interest in sb.

SVO

(a) $\mathrm{S}=$ prototyp. $\mathrm{sb} / \mathrm{sth}$ attractive to $\mathrm{O}$

(b) $\mathrm{O}=$ prototyp. human (Go, Aff)

e.g. His intelligence was what attracted her the most.

SVO

(a) $\mathrm{S}=$ prototyp. human-like artifact <book, work, play etc. $>$, attractive to $\mathrm{S}$ (Ag). This will be a case of metonymy <product for producer>.

(b) $\mathrm{O}=$ prototyp. a positive quality or reaction (Go, Aff)

e.g. The high-handed way he dealt with the situation attracted a good deal of criticism. 
The majority of the verbs in this dimension lexicalize extremely negative bodily reactions such as disgust, sicken and nauseate. In consonance with the fact that body and mind are not different, but two sides of the same whole, a negative emotion affects our mental and physical balance (Kövecses 1986, Lakoff 1987), something which is reflected in the definitions of the following verbs.

(24) To cause aversion / dislike in sb producing anger

madden: to anger $\mathrm{sb}$, causing them to become insane.

To cause sb to feel fear /anxiety

agitate: to cause sb to feel so worried that they are unable to think clearly or act calmly.

upset: to cause sb to feel worried, taking away their peace of mind and making them feel unhappy.

To cause aversion /dislike in sb producing disgust

sicken: to make sb feel so disgusted that they do not feel well.

nauseate: to sicken sb so that they feel as if they are going to vomit.

\section{Towards the establishment of a Semantic Macronet}

In our view, the lexicon is in itself a grammar, and accordingly this should be subjected to certain standards of adequacy: (i) typological (ii) psychological and (iii) textual. In elaborating a semantic macronet, we are in fact working on the textual adequacy of the lexicon. This means that according to this standard of adequacy, the lexicon is conceptualized as an intricate network of elements interconnected by cohesive, associative, lexical and encyclopedic functions. These could most clearly be represented by links between words in a network of cross-references within a relational model of the lexicon.

The establishment of a semantic net will not only reflect the internal structure of a our lexicon/dictionary, but will also tell us a great deal about ourselves and the way we interact with the world. Consequently, the organization of words within the lexicon is meaningful because among other things, the structures formed by semantic connections are representations of categorizing relationships. On the basis of the analysis we have carried out of the definitional structure of English verbs and their subcategorization patterns, we have established a hierarchy of the different fields (primary connections and dependencies). However, since field interrelationships are multiple and various, each field can be said to have a set of secondary connections as well. These secondary connections can be seen, for example, in the double field membership of certain verbs in which one set of meaning components or another is highlighted, according to the area of meaning it is located in. 
Each field has a primary location within the lexicon in which we see its most important relationships with other domains. The names of fields in their primary locations are written in capital letters. The fields in lower case letters indicate the existence of secondary relationships in which certain lexemes can be said to have double field membership. The field membership of a verb depends on which meaning component within its definition is highlighted. For example, fields related to EXISTENCE have BE (the definition of EXISTENCE) as the nuclear part of the definition of the archilexeme. This lexical dependence also reflects a conceptual dependence. Basic fields such as EXISTENCE, MOVEMENT, POSITION, and CHANGE are precisely those which underlie virtually all structured lexical representations. In reference to the relatively simple ideas of EXISTENCE and POSITION IN SPACE, PROPERTY/STATE, Apresjan (1993:83) states:

'These ideas [EXISTENCE, POSITION IN SPACE, PROPERTY/STATE] underlie various lexical meanings of the overwhelming majority of physical action verbs and thus form the semantic foundation of the verbal lexicon in a great many languages. They model the most elementary situations in which real word objects occur and are contemplated by the speakers.'

As can clearly be observed, there are close interfield relationships, the existence of which has led us to postulate a macrostructure for the lexicon (see Appendix 1). The fields in lower case levels indicate the existence of secondary relationships in which certain lexemes can be said to have double field membership. The more basic a field is, the greater number of connections it will have with other fields.

\subsection{The lexical field of FEELING and its connections with other fields}

In the case of the lexical field of FEELING, MOVEMENT, CHANGE, and POSSESSION are the basic target domains. For example, attraction means that we move towards something in order to get it. Conversely, repulsion means that we move away from it for just the opposite reason. Moreover, a person who experiences an emotion or feeling, moves from one state to another, and thus undergoes a change, (e.g. sadden).

\subsubsection{FEELING and MOVEMENT}

Extensions towards movement are represented by the following dimensionalschemas: to cause sb to feel, to cause attraction or interest in sb, to cause aversion or dislike, and to cause a loss of attraction or interest.

In the causative dimension, to cause sb to feel, there is another basic connection with the field of MOVEMENT. If something moves you, it causes you to feel a fairly 
strong emotion. The movement involved is from some hypothetical normal state of feeling to a different one that is necessarily a deviation from normal values. The fact that the type of emotion involved is invariably one of sadness or sympathy for someone else's sad plight is another evidence that the default value in FEELING is not a neutral emotional state but a positive one. In other words, our normal state is happiness and a move away from that state necessarily means a change for the worse:

(25) His words moved me (to tears).

(26) *His words moved me (to laughter).

In the above examples, we can see that while 25 is perfectly acceptable, 26 is so odd as to be impossible. This type of connection with MOVEMENT as we shall see below, also extends to other hyponyms of move, such as stir and agitate. These last examples are violent movements and codify an equivalence between quick, sudden movement and strong, often violent feelings.

Besides being conceptualized as conditions of the body, our feelings are reified as fluids and light within our bodies as containers. This is the base for a wide variety of idiomatic expressions. This reification leads us to a connection with MOVEMENT, which stems from the already mentioned double field membership of move, and is evidenced in verbs such as stir and agitate:

(27) stir $_{1}$ [MOVEMENT]: $\quad$ to cause $s t h$ (esp. a liquid) to move, mixing it usu. with a spoon.

agitate $_{1}$ [MOVEMENT]: to stir a liquid, shaking it violently. stir $_{2}$ [FEELING]: $\quad$ to cause a strong feeling in sb.

agitate $_{2}$ [FEELING] to cause sb to feel so worried that they are unable to think clearly or act calmly.

In MOVEMENT, agitate is a direct hyponym of stir, while in FEELING, the connection is slightly more indirect, because stir is a much more general verb and the strong emotion it refers to is non-specific and can be either excitement or anxiety. Agitate is a hyponym of worry and falls into the extensively lexicalized anxiety group. In the above definitions, we can observe how feelings are conceptualized as liquids. The strength of the feeling is in function with the degree of violence /brusqueness/velocity of the movement.

In the dimension, to cause attraction or interest in $s b$, we observe that the predicates within this dimension (e.g. attract, lure, entice, draw) all imply movement on the part of the affected entity towards the agent or towards some destination of the agent's choice. Other lexical units within this dimension equate attraction with POSSESSION. Here we see an example of spatial event structure within the same 
lexical dimension in that when you cause attraction in somebody, you cause them to move towards you in this case in order to possess them. Whereas attract, lure, entice, and draw lexicalize motion at a secondary level, verbs such as fascinate, captivate, enthral, mesmerize, charm and enchant lexicalize the end result of possession. Of course, within this dimension these verbs do not refer to physical possession, but rather to mental possession in which the desired goal is to catch the person's attention.

\subsubsection{FEELING and CHANGE}

Every field related to MOVEMENT must in turn be related to CHANGE. In FEELING, this relation can be seen in the fact that certain of its verbs are de-adjectival since they lexicalize a change of state in which the experiencer goes from one emotional state to another. Thus we have verbs with the suffix -en, such as sadden, gladden, sicken, and madden. Extensions towards CHANGE are the following: To feel happiness, to feel sadness, and to cause sb to feel physical/mental suffering.

\subsubsection{FEELING and TACTILE PERCEPTION}

It is significant that one of the archilexemes in the field of FEELING is also the superordinate term in the field of TACTILE PERCEPTION. It is used to convey the effect of the physical stimulus on the perceiver. This verb is a clear instance of the close relationship between the physical and the non-physical dimensions of experience, as it is used to denote the inner perception of a non-physical stimulus. The fact that our emotions are linked to the sense of touch instead of one of the other senses is significant because when we touch something (or something touches us), we do not necessarily understand what it is, but we do sense whether it gives us pleasure or not. This is a direct contrast with see [VISUAL PERCEPTION] which also means understand within the field of COGNITION.

\subsubsection{FEELING and VISUAL PERCEPTION}

In the dimension, to feel attraction or interest, there is also a strong link with VISUAL PERCEPTION because when someone is attractive to us, it is difficult to separate VISUAL and MENTAL PERCEPTION (COGNITION). When we love someone for what they are, they also become physically attractive to us. Thus to love someone is also to love to look at them. However, love does not imply knowledge, just as looking does not necessarily imply seeing. As a result, it is hardly a contradiction that most of the verbs can be modified by the adverb blindly. 
(28) Despite the way he treated her, she loved / adored/worshipped him blindly.

The clearest case of looking and feeling can be observed in the verb admire in which you like someone and look at them at the same time. At the negative pole, exactly the same thing occurs in gloat, when you look at someone and feel great pleasure that something bad has happened to them. These verbs are among the few in which the nuclear part of the definition of the verb is a coordinated structure (looking and feeling). This reflects the type of connection existing between the two fields in which both are of equal importance.

\subsubsection{FEELING and COGNITION}

The dimension, to feel surprise, is directly linked to COGNITION in that it is generated by the perception of something the experiencer finds impossible to believe. Surprise can be either positively or negatively-valued depending on its context. Depending on the intrinsic qualities of the perceived entity, the feeling of surprise will be agreeable or disagreeable, and the axiological weight of the verbs will be affected accordingly.

(29) pos. evaluation:

His good fortune surprised/astonished/stunned/amazed/astounded him.

(30) neg. evaluation

Her sudden death surprised/astonished/stunned/amazed/astounded him.

As we have mentioned, the area of negatively-valued experience often has a much richer lexical structure, because negativity is a deviation from the positive expectations that are the default settings in our perception of the world. The same is true for verbs in the dimension of to cause a loss of attraction/interest such as tire, weary, fatigue and exhaust. Their basic meaning referring to physical experience has been extended into the realm of mental experience, a phenomenon which occurs repeatedly throughout the lexicon.

Within the definitions of the verbs in this field, we can see that feeling and thought are conceptualized as two very different things. Feeling and cognition can have the following cause and effect relationships:

(31) Feelings caused by mental processes:

despise to not like sb/sth because you think that their quality, standard or behaviour is very low.

worry to experience anxiety because you keep thinking about bad things that may happen to you. 
(32) Feelings that cause mental processes:

mesmerize to fascinate somebody in a hypnotic way, making it impossible to think about anything else.

humble to humiliate $\mathrm{sb}$, making them realize that they are not so important or powerful as they had thought.

\section{Conclusions}

In this paper we have analyzed the lexical field of FEELING structured in hierarchies of meaning and subcategorization patterns as the codification of knowledge representation. We have used the hierarchical nature of the dimensionlevel schemata that define this lexical field to show how hierarchical grading reflects conceptual saliency. Finally, we have outlined the connections FEELING establishes with other domains.

Language shows that our feelings are a bridge between the physical and mental or between the mental and physical because the path can go either way. Acting as a link between mind and body, our emotions are naturally complex, and this complexity is also mirrored in our mental representation of feeling as codified in lexical structure.

\section{Appendix 1}

\section{SEMANTIC NETWORK}

1. EXISTENCE: To be in space or time

1.1. POSITION: To be in a particular state/condition/ position without moving/changing.

1.2. MOVEMENT: To begin/continue/stop existing

1.3. POSSESSION: To have (for $\mathrm{sth} / \mathrm{sb}$ to be with you/ as a part of you).

1.4. action (make): To cause sth to be [create] by making it.

1.5. action (do): To cause sth not to be by doing sth (carrying out a specific action) [end, cancel].

1.6. perception [physical \& mental]:

(i) To be in the perception of others [appear]

(ii) To begin to be in the perception of others [arise]

1.6.a. causative perception:

(i) To begin to develop, showing the first signs of sth [dawn].

(ii) To cause to exist in the perception of others [show].

1.6.1. visual perception: To be in the perception of others, becoming visible [surface, materialize, form]. 


\section{7 change:}

(i) To be in the perception of others, becoming visible [surface, materialize, form].

(ii) To be in time, becoming real [happen].

1.7a causative change: to cause sth to be/become [make, render]

1.8 feeling: to be regularly in a certain place, usu. causing fear, problems, worry [haunt].

2. CHANGE: To become different/alike

2.1. PHYSICAL PERCEPTION: To become aware of sth through your senses or experience. [perceive]

2.1.1. speech: To become aware of sth through your senses or experience and say it. [note]

2.1.2. VISUAL PERCEPTION: To become aware of sth with your eyes. [see]

2.1.2.1. LIGHT: stimulus field, necessary for sight [shine].

2.1.3. mental perception: [contemplate, regard]

2.1.4. speech: To become aware of sth with your eyes and say it [observe].

2.1.5. position: To (cause sth) not to be seen because of putting it in a place. [hide, secrete] or putting sth over it [cloak, veil]

2.1.6. AUDITORY PERCEPTION: To become aware of sth with your ears [hear].

2.1.6.1. SOUND, SPEECH: stimulus fields for hearing.

2.1.7. TACTILE PERCEPTION: [touch]

2.1.8. OLFACTORY PERCEPTION: [smell]

2.1.9. TASTE PERCEPTION: [taste]

2.2. MENTAL PERCEPTION: To become aware of sth in your mind [know].

2.2.1. speech:

(a) To become aware of sth in your mind and say it [reason].

(b) To (try to) cause sb to think sth is true by saying things to them [persuade]

(c) To cause sb to think sth is true by telling them things that are untrue [con].

2.2.2. visual perception:

(a) To become aware of sth in your mind as though you are seeing it. [see]

(b) To cause sb to be aware of sth in their mind by causing it to be seen $[$ show $]$. 
2.2.2.1. light: To cause sb to be aware of sth in their mind by causing it to be seen as though by shining a light on it. [illuminate]

\subsection{3. possession/tactile perception:}

To become aware of sth in your mind as though by getting hold of it in your hand [ grasp].

\subsection{4. possession:}

To cause sb to think sth is true when it is not in order to take sth away from them [defraud, swindle].

\subsection{5. action:}

(a) To cause sb to become aware of sth by doing sth [publicise]

(b) To cause sb to think that sth is true when it is not to make them do sth you want them to. [dupe].

\subsection{6. change/existence:}

To think that sth is going to become real (happen) [expect].

2.3. FEELING: To experience (become aware of a feeling/ experience/ sensation

\subsection{1. visual perception:}

(a) To feel attracted to sb/sth, perceiving them visually (looking on them) with interest/approval. [admire]

(b) To feel pleasure at sb else's misfortune and show it by your facial expression. [gloat]

\subsection{2. speech:}

(a) To feel sth, expressing that feeling in words. [fuss, fret]

(b) To cause sb to feel a certain way by saying words to them.

2.3.3. action: To cause sb to feel pain /pleasure by doing sth. [hurt, punish]

2.4. movement: To move (To change from one place/position to another).

2.5. action: To become/cause to become different by doing sth. [straighten, widen, etc.]

3. ACTION: To do/make sth

3.1. USE: To do sth with sth else to get a certain result.

3.1.1.speech: To use your mouth to speak/say words.

To use sth to speak/say words [telephone]

3.2. feeling: To do sth causing sb/sth to feel sth (pain, pleasure, etc.) [torture, punish, spank]

3.3. possession: To do sth to have sth else.

3.4. change: To do sth that causes sth to become different. [clean, damage]

3.5. movement:

(a) To do sth by coming together/apart.

(b) To do sth that causes sth to come together/apart. [join, separate] 
(c) To do sth in which sth moves /causing sth to move (with sth else) [rake, plough, ski, etc.]

\section{6. position: To do sth}

(a) to cause sb/sth to be in a place/position (hold, save).

(b) to put sth in/on a particular place (focus on instrument [tape, nail, screw], location [bottle, can, box, etc.], force/difficulty [wedge, jam], substance [paint, wax].

3.7. existence: To make sth, causing it to be. [create]

3.8. mental perception: To do sth to make sth known. [publicize]

3.9. speech: To do sth by saying sth [annul, consecrate, acquit, etc.]

3.10. SLEEP: To not do anything active for a period of time.

The above list is by no means exhaustive, but is meant to be a sketch of what we regard as some of the principal interfield connections.

\section{References}

CONNOLLY, C. and S.C. DIK (eds) 1990. Functional Grammar and the computer. Dordrecht: Foris Publications.

CONNOLLY, J.H. 1990. Functional Grammar and artificial intelligence. In: Connolly, C. and S.C. Dik (eds). Functional Grammar and the computer. Dordrecht: Foris Publications.

COSERIU, E., 1977. Principios de semántica estructural. Madrid: Gredos.

COSERIU, E. y H. GECKLER, 1974. Structural semantics. Tübingen: Narr.

DIK, S.C., 1978a. Functional Grammar. Amsterdam: North Holland.

DIK, S.C., 1978b. Stepwise lexical decomposition. Lisse: Peter de Ridder.

DIK, S.C., 1986. Linguistically motivated knowledge representation. Working Papers in Functional Grammar 9. Amsterdam: University of Amsterdam.

DIK, S.C., 1989. The theory of Functional Grammar. Part I: the structure of the clause. Dordrecht: Foris Publications.

FABER, P. and MAIRAL, R., 1994a. The paradigmatic and syntagmatic structure of the lexical field of EXISTENCE in the elaboration of a semantic macronet. Paper presented at the Sixth International Conference on Functional Grammar, 22-26 August 1994. University College of Ripon and York St John, York.

FABER, P. and MAIRAL, R., 1994b. Methodological underpinnings for the construction of a functional lexicological model. Miscelánea, Zaragoza: University of Zaragoza.

FABER, P. and MAIRAL, R., forthcoming. The semantic architecture of the English verbal lexicon. 
GRIMSHAW, J., 1979. Complement selection and the lexicon. Linguistic Inquiry 10-2, 279-326.

JOHNSON, M. 1987. The body in the mind. Chicago: University of Chicago Press.

KÖVECSES, Zoltán, 1986. Metaphors of anger, pride, and love: a lexical approach to the structure of concepts. Amsterdam: John Benjamins.

LAKOFF, G., 1987. Women, fire, and dangerous things. Chicago: University of Chicago Press.

LAKOFF, G. and JOHNSON, M., 1980. Metaphors we live by. Chicago: University of Chicago Press.

MARTIN MINGORANCE, L., 1984. Lexical fields and stepwise lexical decomposition in a contrastive English-Spanish verb valency dictionary. In: Hartmann, R.R.K. (ed)., LEXeter '83 proceedings. Tübingen: Max Niemeyer.

MARTIN MINGORANCE, L., 1985a. La semántica sintagmática del adjetivo. Parámetros para la organización de un lexicón inglés/español de valencias adjetivales. In: Actas del II Congreso Nacional de la Asociación Española de Lingüística Aplicada, 329-340. Madrid: Sociedad General Española de Librería.

MARTIN MINGORANCE, L., 1985b. Bases metodológicas para un estudio contrastivo del léxico derivado. Revista Española de Lingüística Aplicada 1, 37-54.

MARTIN MINGORANCE, L., 1987a. Classematics in a functional-lexematic grammar of English. In: Actas del X Congreso de la Asociación Española de Estudios Anglo-Norteamericanos, 377-382. Zaragoza: Publicaciones de la Universidad.

MARTIN MINGORANCE, L., 1987b. Semes, semantic classemes, and dimensions: the lexicological and lexicographic perspectives. Paper read at the XIVth International Congress of Linguists, Berlin.

MARTIN MINGORANCE, L., 1987c. Pragmatic features in the lexicon of a Functional Grammar. Paper read at the International Pragmatics Conference. Antwerp.

MARTIN MINGORANCE, L., 1990. Functional Grammar and Lexematics. In: Tomaszczyk, J. and Lewandowska-Tomaszczyk, B. (eds.), Meaning and lexicography, 227-253. Amsterdam: John Benjamins.

MOYERS, B. (ed.), 1993: Healing and the mind. New York: Doubleday. 